\title{
Perbandingan Citra Hasil Rekonstruksi Metode Newton-Raphson dan Landweber pada Electrical Capacitance Tomography: Analisis Resolusi dan Akurasi
}

\author{
Rifang Pri Asmara*, Agung Tjahjo Nugroho, dan Endhah Purwandari \\ Jurusan Fisika, Fakultas Matematika dan Ilmu Pengetahuan Alam, Universitas Jember \\ Jln. Kalimantan X, Sumbersari, Jember 68121
}

\begin{abstract}
Intisari
Penelitian untuk membuat desain Electrical Capacitance Tomography dilakukan menggunakan metode numerik Finite Difference Method (FDM) untuk forward problem dan ditentukan tingkat akurasinya terhadap metode analitik. Solusi berbasis FDM yang diperoleh, digunakan dalam proses rekonstruksi menggunakan metode Landweber dan Newton-Raphson. Perbandingan citra hasil rekonstruksi dari kedua metode dianalisis berdasarkan resolusi dan akurasi citra yang dihasilkan. Hasil penelitian ini menunjukkan bahwa akurasi FDM dengan melakukan pemotongan garis pada objek domain, didapatkan $90,57 \%$ pada garis horizontal dan $87,43 \%$ pada garis vertikal. Adapun hasil untuk rekonstruksi didapatkan akurasi proses rekonstruksi $98 \%$ untuk NewtonRaphson dan 88\% untuk Landweber. Resolusi citra yang direkonstruksi dengan menggunakan Newton-Raphson mampu membedakan 2 benda dengan jarak pisah minimal $3 \mathrm{~cm}$, sedangkan Landweber mampu membedakan 2 benda dengan jarak pisah minimal $8 \mathrm{~cm}$. Hasil akurasi dan resolusi tersebut berlaku untuk sistem ECT 8 elektroda dengan objek domain lingkaran.
\end{abstract}

\begin{abstract}
The Electrical Capacitance Tomography system has been designed using the Finite Difference Method as a forwarding problem-based solution. Accuracy of the solution has also determined with the analytical method. The reconstruction proses using Landweber and Newton-Raphson method has been conducted so that a comparison of resolution and accuracy of the resulting image have obtained. The results of this research, indicate that the accuracy of the Finite Difference Method by cutting a line on a domain object was obtained at $90.57 \%$ on the horizontal line and at $87.43 \%$ on the vertical line. The result of the reconstruction process based on the NewtonRaphson method produced an accuracy of $98 \%$, while the Landweber method only gained $88 \%$. Two objects can be distinguished well using the Newton-Raphson method when they are at least $3 \mathrm{~cm}$ apart. Meanwhile, the other method is only able to distinguish two objects, at a minimum distance of $8 \mathrm{~cm}$.
\end{abstract}

Keywords: Electrical Capacitance Tomography; Finite Difference Method; Landweber; Newton-Raphson.

*Corresponding author: rifang.asmara12@gmail.com

http://dx.doi.org/10.12962/j24604682.v16i1.5238

2460-4682 (C)Departemen Fisika, FSAD-ITS

\section{PENDAHULUAN}

Tomografi adalah teknik pengamatan yang mampu menggambarkan sebuah objek secara cepat dan tidak bersifat merusak atau mengubah struktur benda [1]. Berbagai macam aplikasi dari tomografi yang telah diterapkan adalah menggambarkan anatomi manusia [2], mendeteksi gangguan tulang [3], menentukan defect pada material [4], menentukan kualitas makanan [5], dan monitoring regulasi dari pipa industri [6]. Salah satu jenis tomografi adalah Electrical Capacitance Tomography (ECT), yang memanfaatkan sifat listrik yaitu kapasitansi. ECT bekerja dengan memanfaatkan distribusi kapasitansi yang diukur pada elektroda di permukaan objek, untuk menentukan distribusi permitivitas objek yang diamati. Kelebihan tomografi jenis ECT adalah implementasi yang sederhana karena bekerja pada frekuensi rendah [7]. Agar implementasi dari ECT lebih luas, maka dilakukan sebuah penelitian untuk membuat sistem ECT dan menganalisis tingkat resolusi dan akurasi citra yang dihasilkan pada proses rekonstruksinya.

Pembuatan sistem ECT dilakukan menggunakan dua tahapan. Tahapan pertama yaitu forward problem dengan menentukan distribusi potensial berdasarkan distribusi permitivitas, dan yang kedua adalah invers problem dengan menentukan distribusi permitivitas berdasarkan distribusi potensial [8]. Penyelesaian forward problem dilakukan dengan menggunakan solusi numerik agar didapatkan distribusi potensial pada kondisi permitivitas tertentu. Solusi numerik pada penelitian ini digunakan Finite Difference Method (FDM) atau metode beda hingga untuk menentukan 


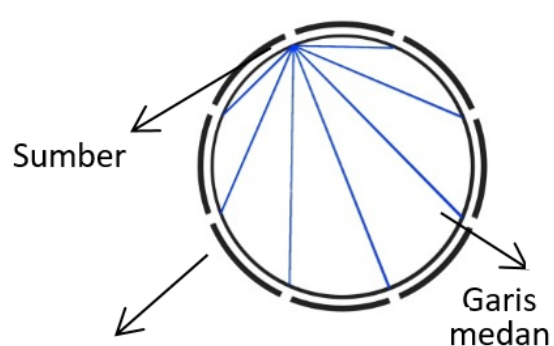

Elektroda a)

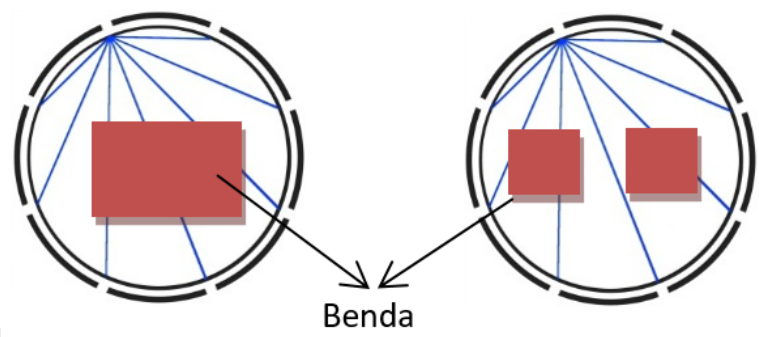

b)

c)

Gambar 1: a). Model objek tanpa benda b). Model objek dengan 1 benda ukuran $20 \times 20 \mathrm{~cm}$ c). Model objek dengan 2 benda masing-masing ukuran $10 \times 10 \mathrm{~cm}$ dengan jarak pisah.

distribusi potensial pada sistem ECT yang digunakan. FDM merupakan metode numerik untuk menentukan nilai potensial di suatu titik yang berdasarkan pada titik-titik disampingnya [9]. Kelebihan metode ini adalah dapat menentukan solusi masing-masing titik dengan mudah dan dapat menggambarkan distribusi potensial keseluruhan yang bersifat distkrit [10]. Pada penelitian ini, solusi numerik yang didesain akan dibandingkan dengan solusi analitik, sehingga didapatkan tingkat akurasi dari solusi numerik.

Bagian selanjutnya, untuk permasalahan invers problem atau rekonstruksi, digunakan dua metode yaitu Landweber dan Newton-Raphson, untuk mendapatkan hasil perbandingan kedua metode tersebut pada tingkat akurasi dan resolusinya. Metode Newton-Raphson memiliki prinsip meminimasi nilai kuadrat error dari selisih pengukuran kapasitansi dengan pendekatan nilai kapasitansi, sehingga didapatkan hasil rekonstruksi yang lebih akurat [11]. Sedangkan metode Landweber, memiliki prinsip optimalisasi dengan selisih hasil rekonstruksi terukur dan hasil rekonstruksi melalui pedekatan, untuk mendapatkan hasil rekonstruksi yang akurat [12]. Dua metode tersebut sudah pernah dilakukan untuk mendesain sistem tomografi, seperti rekonstruksi ECT menggunakan Newton-Raphson [13], dan rekonstruksi ECT menggunakan Landweber [14]. Pada penelitian ini, akan dilakukan rekonstruksi menggunakan dua metode tersebut, dan selanjutnya akan dianalisis tentang tingkat akurasi dan resolusi yang dihasilkan.

\section{METODOLOGI}

Penelitian ini dibagi menjadi beberapa tahapan yaitu pembuatan model objek, penyelesaian forward problem, penyelesaian invers problem, dan analisis akurasi dan resolusi citra hasil rekonstruksi. Masing-masing tahapan memiliki peranan penting untuk membuat sistem ECT dan proses analisisnya.

\section{Pembuatan model objek}

Pembuatan model objek ECT dilakukan dengan mendesain sistem ECT berbentuk lingkaran dengan 8 elektroda yang disusun pada permukaannya dengan sumber tegangan 50 volt, seperti yang ditunjukan pada Gambar 1.

Model objek yang ditunjukan pada Gambar 1 menggunakan 8 elektroda, dan selanjutnya akan dibuat cacahan dengan jumlah grid persegi $(50 \times 50) \mathrm{cm}^{2}$ untuk mendesain solusi numerik dan hasil rekonstruksi pada titik-titik grid-nya. Model objek dengan permitivitas yang dijadikan background adalah 1, sedangkan benda memiliki permitivitas 7 , dengan ukuran $\left(20 \times 20 \mathrm{~cm}^{2}\right)$ dan $(10 \times 10) \mathrm{cm}^{2}$ pada jarak pisah $10 \mathrm{~cm}$. Pengukuran dilakukan untuk satu elektroda sebagai sumber sedangkan 7 elektroda lain digunakan untuk menentukan kapasitansi. Proses tersebut dilakukan dengan pergantian sumber untuk elektroda yang lain.

\section{Penyelesaian forward problem}

Penyelesaian forward problem digunakan untuk menentukan distribusi potensial $\phi$ yang diperoleh dengan menyelesaikan persamaan Poisson [15].

$$
\nabla \bullet \epsilon \nabla \Phi=-\rho
$$

dengan $\rho$ adalah rapat muatan dan $\epsilon$ adalah permitivitas benda. Selanjutnya, Pers.(1) dikorelasikan dengan variabel kapasitansi sehingga mendapatkan persamaan kapasitansi yang bergantung pada distribusi permitivitas $\epsilon$, untuk dua elektroda yang memiliki beda potensial $\Delta V_{i j}[16]$.

$$
C_{i j}=-\frac{1}{\Delta V_{i j}} \int_{T} \epsilon(x, y) \nabla \Phi(x, y) d \ell
$$

Nilai kapasitansi $C_{i j}$ merupakan nilai yang diukur pada setiap pasangan elektroda, dimana $C_{i j}$ merupakan fungsi integral permitivitas dan gradien potensial untuk koordinat $\mathrm{x}$ dan y terhadap $\mathrm{d} \ell$, sehingga penelitian ini menghasilkan 56 hasil pengukuran kapasitansi untuk model objek yang digunakan. Berdasarkan Pers.(2), dapat diambil sebuah matrik yang menghubungkan antara variabel kapasitansi dan variabel permitivitas, yang disebut sebagai matrik sensitivitas $S_{i j}$ [17].

$$
S_{i j}=\int_{A} \frac{\nabla \Phi_{i} \bullet \nabla \Phi_{j}}{V_{i} V_{j}} d A
$$




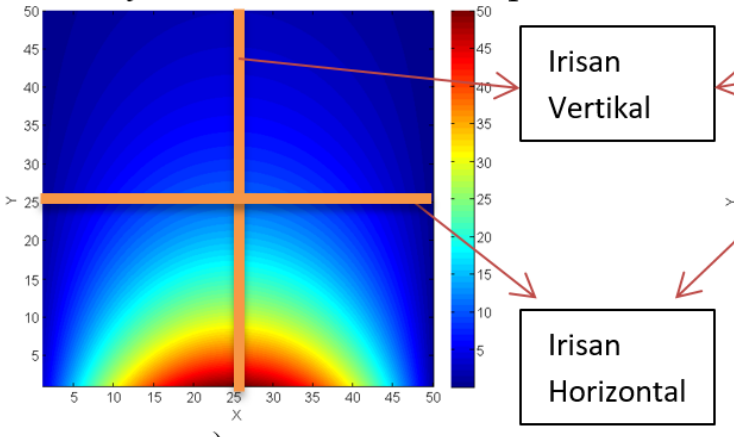

a)

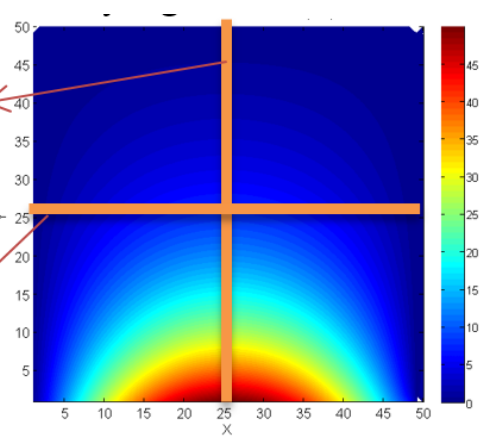

b)

Gambar 2: a). Distribusi potensial dengan solusi analitik b). Distribusi potensial dengan solusi numerik FDM.

\section{Penyelesaian invers problem atau rekonstruksi}

Terdapat dua metode yang digunakan pada proses rekonstruksi yaitu metode Newton-Raphson dan metode Landweber. Persamaan yang digunakan dalam metode NewtonRaphson ditunjukkan oleh Pers.(4) [18].

$$
G_{k+1}=G_{k}+\left(S_{k}^{T} \bullet S_{k}+\gamma I\right)^{-1} S_{k}^{T}\left(C_{k}-C\right)
$$

Sedangkan persamaan dari metode Landweber ditunjukkan oleh Pers.(5) [19].

$$
G_{k+1}=G_{k}+\alpha_{k} \bullet S^{T}\left(C-S \bullet G_{K}\right)
$$

Kedua metode tersebut digunakan untuk menentukan distribusi permitivitas hasil rekonstruksi $\mathrm{G}$ berdasarkan hasil pengukuran nilai kapasitansi C. Kedua metode akan diberlakukan pada jumlah iterasi 1 hingga 100.000 untuk mendapatkan hasil rekonstruksi yang baik.

\section{Analisis akurasi forward problem, akurasi proses rekonstruksi, dan resolusi}

Akurasi solusi numerik yang diperoleh menggunakan FDM diperbandingkan dengan solusi analitik. Seleksi terhadap model objek yang akan ditentukan nilai akurasinya, dilakukan dengan cara mengambil daerah hasil slicing di bagian garis tengah objek domain. Hasil slicing akan menghasilkan garis horisontal dan garis vertikal untuk ditentukan nilai akurasinya. Perhitungan error dari solusi numerik mengunakan FDM dilakukan dengan Pers.(6) dengan V adalah variabel potensial.

$$
\text { error }=\frac{\left|V_{\text {numerik }}-V_{\text {analitik }}\right|}{V_{\text {analitik }}} \times 100 \%
$$

Adapun error untuk proses rekonstruksi ditunjukkan pada Pers.(7).

$$
\text { error }=\frac{\|S G-C\|}{\|C\|^{2}} \times 100 \%
$$

Berdasarkan data error di atas, tingkat akurasi ditentukan dengan menggunakan Pers.(8).

$$
\text { akurasi }=100 \%-\text { error }
$$

Pengukuran resolusi ditentukan dengan mengamati jarak pisah minimum 2 buah benda hasil rekonstruksi yang masih dapat dibedakan satu sama lain. Jarak pisah diambil mulai dari jarak $10 \mathrm{~cm}$ dan diperkecil dengan interval $1 \mathrm{~cm}$. Jarak minimum yang diperoleh menunjukkan kemampuan sistem ECT untuk membedakan 2 benda yang terpisah.

\section{HASIL DAN PEMBAHASAN}

Hasil penelitian ini dibagi menjadi 3 bagian. Bagian pertama yaitu hasil penyelesaian forward problem, bagian kedua yaitu penyelesaian invers problem, dan bagian ketiga adalah resolusi citra hasil rekonstruksi.

\section{Hasil penyelesaian forward problem}

Penyelesaian forward problem menggunakan FDM dan solusi analitik pada kasus sederhana atau permitivitas homogen berupa distribusi potensial yang ditunjukkan pada Gambar 2. Solusi analitik pada Gambar 2 didapatkan dari penyelesaian persamaan Laplace dengan memberikan syarat batas $\mathrm{v}(\mathrm{x}, 0)=50 \sin (\pi \mathrm{x} / 50)$ volt, $\mathrm{v}(\mathrm{x}, \propto)=0$, dan ekspansi deret menggunakan deret Fourier [19]. Sedangkan solusi numerik menggunakan syarat batas $\mathrm{v}(\mathrm{x}, 0)=50 \sin (\pi \mathrm{x} / 50)$ volt. Syarat batas tersebut dipilih karena fungsi sinus akan menghasilkan potensial tertinggi pada posisi tengah, dimana posisi tersebut adalah posisi dari elektroda pertama pada sistem ECT yang dibuat.

Hasil akurasi solusi numerik terhadap solusi analitik pada titik-titik yang ditentukan, memiliki akurasi rata-rata yaitu $90,57 \%$ pada garis horisontal, dan $87,43 \%$ pada garis vertikal. Hasil akurasi FDM yang diperoleh dapat dikatakan tinggi karena memiliki tingkat akurasi lebih dari $80 \%$, sehingga solusi numerik FDM dapat digunakan untuk mendesain matrik sensitivitas pada sistem ECT.

\section{Hasil penyelesaian invers problem}

Penyelesaian invers problem menggunakan dua metode yaitu Newton-raphson dan Landweber. Hasil rekonstruksi dua metode tersebut ditunjukkan pada Gambar 3. 


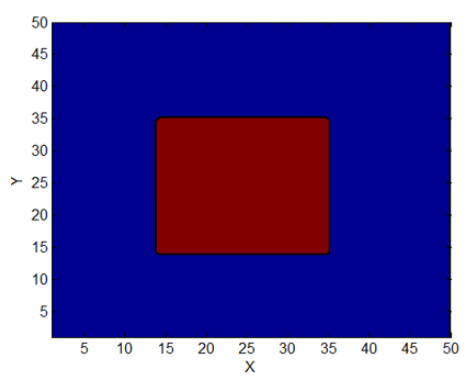

a)

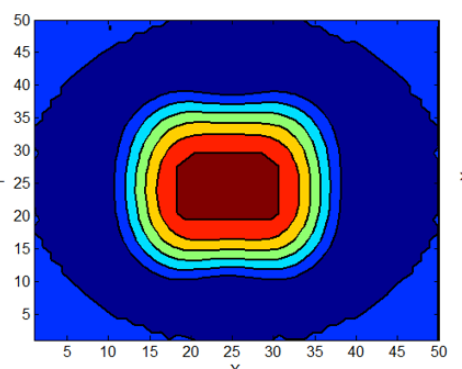

b)

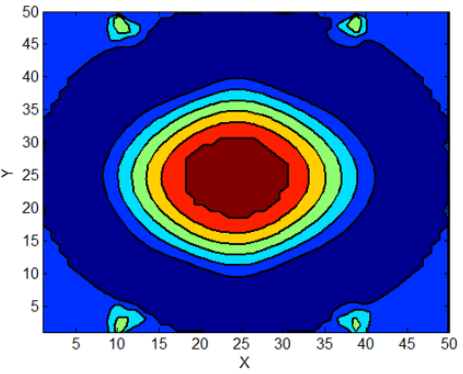

c)

Gambar 3: a). Distribusi permitivitas benda asli, b). hasil rekonstruksi Newton-Raphson, c). hasil rekonstruksi Landweber.

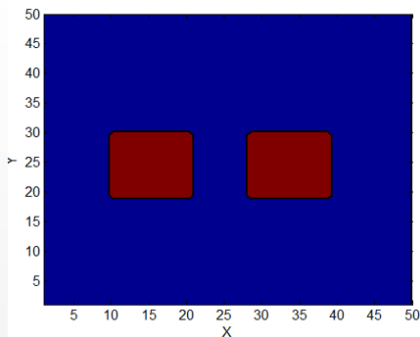

a)

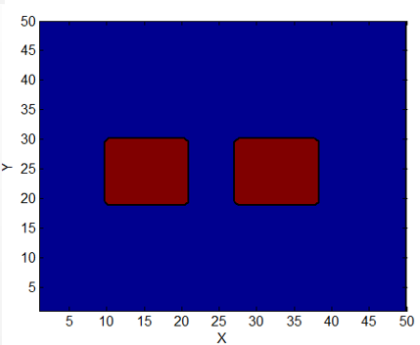

d)

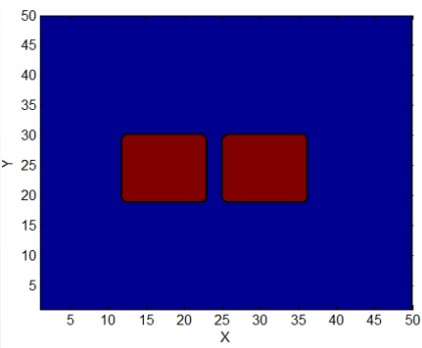

g)

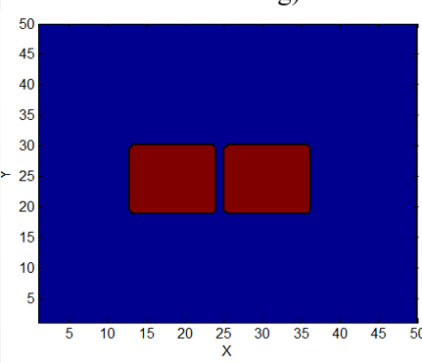

j)

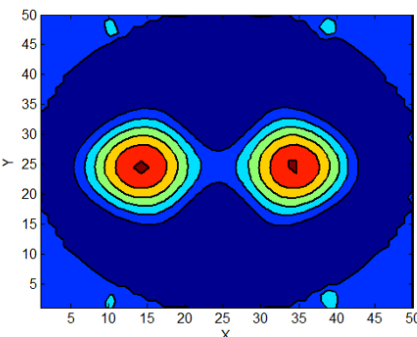

b)

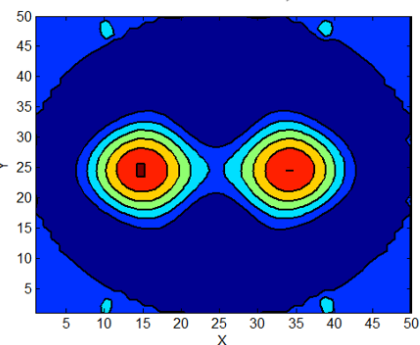

e)

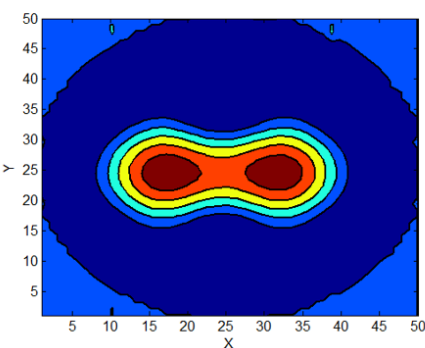

h)

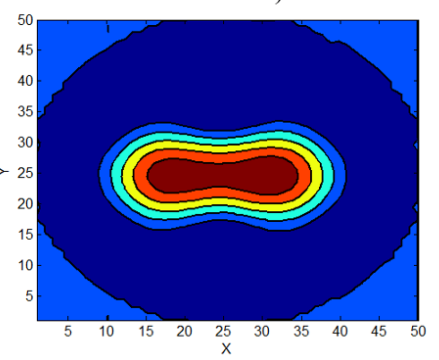

k)

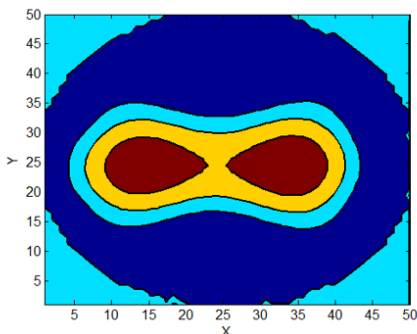

c)

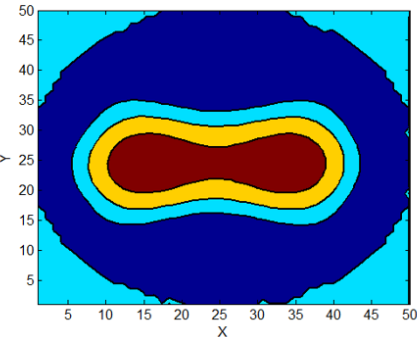

f)

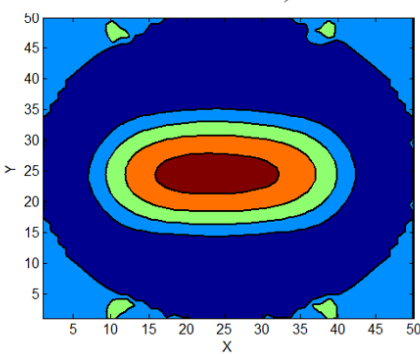

i)

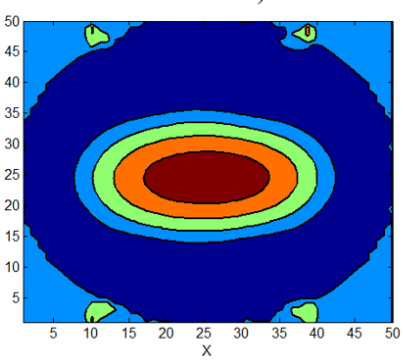

1)

Gambar 4: a) Benda asli berjarak pisah $8 \mathrm{~cm}$. b) Hasil rekonstruksi Newton-Raphson berjarak pisah $8 \mathrm{~cm}$. c) Hasil rekonstruksi Landweber berjarak pisah $8 \mathrm{~cm}$. d) Benda asli berjarak pisah $7 \mathrm{~cm}$. e) Hasil rekonstruksi Newton-Raphson berjarak pisah $7 \mathrm{~cm}$

. f) Hasil rekonstruksi Landweber berjarak pisah $7 \mathrm{~cm}$. g) Benda asli berjarak pisah $3 \mathrm{~cm}$. h) Hasil rekonstruksi Newton-Raphson berjarak jarak $3 \mathrm{~cm}$. i) Hasil rekonstruksi Landweber berjarak pisah $3 \mathrm{~cm}$. j) Benda asli jarak $2 \mathrm{~cm}$. k) Hasil rekonstruksi Newton-Raphson jarak $2 \mathrm{~cm}$. 1) Hasil rekonstruksi Landweber jarak $2 \mathrm{~cm}$. 
Hasil pada Gambar 3 menunjukkan bahwa metode NewtonRaphson dapat merekonstruksi citra lebih baik daripada Landweber, dengan tingkat akurasi pada Newton-Raphson mencapai $98 \%$, sedangkan untuk Landweber mencapai $88 \%$. Selain tingkat akurasi, berdasarkan Gambar 3 dapat dilihat bahwa rekonstruksi Newton-Raphson memiliki bentuk yang lebih mirip benda asli daripada rekonstruksi Landweber. Namun, kedua metode memiliki hasil rekonstruksi dengan efek smoothing. Efek ini menghasilkan sebuah citra yang memiliki perbedaan kontur yang memiliki arti perubahan nilai permitivitas pada permukaan benda, sehingga efek tersebut akan mengganggu hasil rekonstruksi yang dihasilkan oleh sistem ECT.

Selain efek smoothing yang dihasilkan, citra hasil rekonstruksi kedua metode memiliki kelemahan berupa keadaan tidak dapat menggambarkan benda lancip atau memiliki sudut. Hal ini dapat dilihat pada citra hasil rekonstruksi bagian ujung benda, dimana kedua metode tidak dapat menggambarkan bentuk benda secara sempurna. Selain itu, hasil rekonstruksi Landweber masih menghasilkan citra yang berbentuk mirip lingkaran, hal ini berbeda seperti yang dihasilkan oleh Newton-Raphson, dimana Newton-Raphson hanya membentuk lengkungan pada ujung sisi dari benda yang diamati. Adapun hasil dari efek smoothing dan kelemahan dalam merekontruksi benda yang memiliki sudut, citra yang dihasilkan dengan permitivitas 7 mengalami reduksi ukuran. Benda asli dengan ukuran $(20 \times 20) \mathrm{cm}^{2}$ pada permitivitas 7 hanya dapat direkonstruksi menjadi benda berukuran $(12 \times 12) \mathrm{cm}^{2}$ untuk permitivitas 7 . Sedangkan 8 $\times 8 \mathrm{~cm}^{2}$ sisanya merupakan hasil dari efek smoothing yang diperoleh pada proses rekonstruksi.

\section{Analisis resolusi}

Resolusi yang didapatkan merupakan tingkat kemampuan proses rekonstruksi membedakan dua benda yang terpisah dengan jarak tertentu. Hasil citra dua metode yang digunakan untuk menentukan resolusi dapat dilihat pada Gambar 4.

Hasil pada Gambar 4 menunjukkan bahwa metode NewtonRaphson dapat membedakan dua benda dengan jarak $\geq 3 \mathrm{~cm}$, sedangkan pada metode Landweber dapat membedakan dua benda dengan jarak $\geq 8 \mathrm{~cm}$. Oleh karena itu, resolusi yang dihasilkan oleh metode Newton-Raphson lebih baik daripada yang dihasilkan oleh metode Landweber pada penelitian ini.

\section{SIMPULAN}

Berdasarkan hasil penelitian yang telah dilakukan, didapatkan bahwa solusi numerik menggunakan FDM dapat digunakan untuk menyusun sistem ECT karena memiliki akurasi $>80 \%$ terhadap solusi analitik pada kasus permitivitas homogen. Hasil rekonstruksi citra menggunakan metode Newton-Raphson memiliki akurasi dan resolusi yang lebih tinggi dibandingkan dengan metode Landweber, untuk sistem ECT yang didesain pada penelitian ini.
[1] Q. Marashdeh, Warsito, L. Fan, and F.L. Teixeira, "Non-linier Forward Problem Solution for Electrical Capasitance Tomography using Feed-Forward Neural Network", IEEE Sensors Journal, vol 6, pp. 441-449, 2006.

[2] A. Balzeau, D.H. Griamaud, E. Indriati, and T. Jacob, "Computer Tomography Scanning of Homo Erectus Crania Ngandong 7 from Java", Berkala Ilmu Kedokteran, vol 35, pp. 133140, 2003.

[3] D. Demirbag, and Kabayel, "The Role of Quantitative Computed Tomography and Magnetic Resonance Imaging in Diagnosis and Follow-up of Osteoporosis", Turkish Journal of Physics Medicine and Rehabilitation, vol 62, pp. 22-25, 2016.

[4] A. Zbrowski, "X-ray Tomography in The Diagnostics of Roller Bearing Rings", Solid State Phenomena, vol 223, pp. 211-220, 2015.

[5] M.S. Stubkjaer, "Detection of Meat and Fat Quality in Pork and Beef Using X-ray", Thesis, University of Copenhagen, Denmark, 2009.

[6] N. Ramli, K. Shaunmugam, and S. Amir, "Proptosis Correlation and Agreement between Hartel Exophthalmometry and Computed Tomography", The International Journal on Orbital Disorders. Oculoplastic and Lacrimal Surgery, vol 34, pp. 257262, 2015.

[7] Warsito, "Review: Komputasi Tomografi dan Aplikasinya dalam Proses Industri”, Prosiding Semiloka Teknologi Simulasi dan Komputasi serta Aplikasi, Pusat Pengkajian dan Penerangan Teknologi Informasi dan Elektronika (P3TIE-BPPT), pp. 1-11, 2005.
[8] W.Q. Yang, D.M. Spink, T.A. York, and H. McCann, ”An Image Reconstruction Algorithm Based on Lanwebers Iteration Method for Electrical Capacitance Tomography”, Measurement Science and Technology, vol 10, pp. 979-1104, 1999.

[9] R. Shangjie, D. Feng, X. Youyuan, and T. Chao, "Reconstruction of The Three-Dimensional Inclusion Shapes Using Electrical Capacitance Tomography", Measurement Science and Technology, vol 25, pp. 403-414, 2014.

[10] S. Zhao, and J. Matthew, "Some Refinement on The Finite Differenece Method for 3-D dc Resistivity Modeling", Geophysics, vol 61, pp. 1245-1569, 1996.

[11] S.H. David, "Electrical Impendance Tomograph: Method. History and Application", IOP Publishing Ltd., London, 2005.

[12] L. Charles, "Applied Iterative Methods", A K Peters/CRC Press., New York, 2007.

[13] R. Martin, A. Ortiz, and C. Rodriguez, "Multiphase Flow Reconstruction in Oil Pipelines by Capacitnce Using Simulated Anneling", Geofisica Internacional, vol 44, pp. 241-250, 2005.

[14] T.S. Pan, and A.E. Yagle, "Acceleration of Landweber-Type Algoritms by Suppression of Projection on the Maximum Singular vector", IEEE transactions on medical imaging, vol 45, pp. 2023-2027, 1992.

[15] L.M. Boas, "Mathematical Method in The Physics Sciences", John Willey \& Sons, USA, 1983.

[16] M. Soleimani, H. Wang, Y. Li, and W. Yang, "A Comparative Study of 3D Electrical Capacitance Tomography", International Journal of Information and Systems Sciences, vol 3, pp. 292306, 2007. 
[17] F. Wang, Q. Marashdeh, L. Fan, and Warsito, "Electrical Capacitance Volume Tomography: Design and Applications", Sensors (Basel), vol 10, pp. 1890-1917. 2007.

[18] M.S. Beck, and R. Williams, "Process Tomography: A European Innovation and its Application", Meas. Sci. Technol., vol
7, pp. 215-224, 1996.

[19] D.J. Griffiths, "Introduction to Electrodynamics", PrenticeHall, Inc., UAS, 1999. 